Fecha de recepción: marzo 2012 Fecha de aceptación: junio 2012 Versión final: marzo 2013

\section{Subjetividad, creatividad y acción colectiva}

Sylvia Valdés *

\begin{abstract}
Resumen: Se puede apreciar hoy una combinación de la subjetividad creadora y la acción conjunta . Para comprender mejor esas manifestaciones y analizar sus alcances es indispensable plantearse la importancia que tienen, en el panorama actual, los temas de la subjetividad, la creatividad y sus imbricaciones en el marco de la acción colectiva.
\end{abstract}

Palabras clave: acción colectiva - creatividad - subjetividad.

[Resúmenes en inglés y portugués en la página 184]

${ }^{(*)}$ Doctora en Historia de L’Ecole de Hautes Etudes de Sciencies Sociales de París. Fellowship del Centro de Estudios Latinoamericanos de la Universidad de Cambridge. Profesora titular de la Facultad de Arquitectura, Diseño y Urbanismo de la Universidad de Buenos Aires.

\title{
Introducción
}

En el campo del arte y del diseño los movimientos más significativos, cuyos efectos siguen vigentes en la actualidad, han respondido siempre a la acción colectiva. Dadá, el Surrealismo, la Bauhaus, el Vkhutemas y las vanguardias latinoamericanas de los años 20 y 30 fueron el resultado de un compromiso individual y de una movilización colectiva.

Esta combinación de subjetividad creadora y acción conjunta se repite hoy en día en el marco de los acontecimientos políticos que tienen lugar especialmente en Europa y que fueron precedidos de acciones similares durante las crisis latinoamericanas, especialmente en la Argentina. Estos casos muy diferentes presentan ciertos trazos comunes: no se trata de una simple participación en un movimiento colectivo sino la afirmación de un compromiso personal. Esto proporciona otra dimensión a estos movimientos que son pensados y vividos como la búsqueda de nuevas identidades subjetivas y creativas que aportan una crítica en actos a la sociedad actual. Para comprender mejor esas nuevas manifestaciones y analizar sus alcances es indispensable plantearse la importancia que tienen, en el panorama actual, los temas de la subjetividad, la creatividad y sus imbricaciones en el marco de la acción colectiva. 


\section{Subjetividad, psicoanálisis y filosofía}

En sus avances más audaces el psicoanálisis actual, lacaniano, propone una teoría del sujeto como unidad surgida y determinada por la falta (el vacío, la nada, el cero, según la deriva elegida) y en busca de un imposible donde figura el deseo metonímico. Ese sujeto sometido a la ley de Uno que Lacan llama el Nombre del Padre, sujeto de la filiación o sujeto hijo está sometido a las leyes del clan, de la familia y también del Estado y del organismo social. Este sujeto unario en el que se despliegan dos instancias inconsciente/conciente, muestra desde las primeras gestualidades infantiles una acción de rechazo frente a las imposiciones externas que Freud ejemplifica a través del juego Fort Da, el Ausstossung o Verwerfung, que indica una operación biológica de base (Ver Sigmund Freud Obras completas Ed. Amorrortu). Con este juego preverbal se instituye la función simbólica en la cual Lacan ve una "censura al orden social" (Lacan, 1978).

Sin embargo esta censura y el sujeto que ella instala no se comportan según una ley universal. Deleuze y Guattari en El Antiedipo que tiene por subtítulo Capitalismo y esquizofrenia trazan la evolución de la aparición de esta censura a través de la historia de la humanidad y del desarrollo de las fuerzas productivas y de los modos de producción correspondientes. En Mil mesetas y Que es la filosofía, las dos obras que llevan el mismo subtítulo y completan la trilogía se encara con profundidad este devenir y las modalidades creativas que se derivan de las diversas actitudes del sujeto. El proceso que se describe en Mil mesetas no es solamente una topologización o una dinámica espacial subsumible al sujeto sino que encara diversos escenarios y diversas modalidades del proceso de significación. En Que es la filosofía los autores realizan una caracterización del pensamiento según tres grandes formas: filosofía, ciencia, arte. Las mismas quedan definidas según el modo en que cada una de ellas intercepta el caos. El estado caótico no implica una noción de desorden. Los autores definen el caos como una "velocidad infinita" del pensamiento en la cual "se esfuma cualquier forma que se esboce en su interior" (Deleuze y Guattari, 1993).

Esta concepción del pensamiento coincide con la concepción marxista del sujeto que parte de la dialéctica hegeliana y, como ésta, aparta la negatividad. Para el marxismo el sujeto es un átomo relacionado con otros en el interior de un proceso objetivo. Esta concepción del sujeto es heredera directa de Feuerbach. Se sabe que el materialismo dialéctico de Marx se separa de la metafísica naturalista de Feuerbach reintroduciendo la dialéctica y las nociones de lucha, contradicción y práctica. En 1868, Marx le escribe a Hegel, a propósito de Dühing: "Estos señores de Alemania creen que la dialéctica de Hegel es una historia enterrada. A propósito de esto Feuerbach tiene un gran peso en la conciencia” (Mc Lelland, 1972). El marxismo heredará dos aspectos del análisis feuerbachiano:

1) la unificación de la negatividad hegeliana en el hombre, en el sujeto que buscará su deseo, el sujeto proletario a través de una extensión de su acción individual a la de otros compañeros de lucha llevará al advenimiento del hombre nuevo y de un mundo mejor.

2) el anclaje directo y exclusivo del hombre en el Estado y en la maquinaria social que regula las relaciones sociales de producción y de clase. 
Lejos de ser hipótesis complejas estas dos coincidencias en dos concepciones filosóficas de la sociedad casi antagónicas, se deben a que la gran diferencia entre las dos doctrinas subyace en su consideración de la naturaleza y la cultura.

En el contexto cultural forjado a partir de fines del siglo XIX es a la vanguardia artística a la que le corresponde ejemplificar la disolución materialista de la negatividad hegeliana a través de una práctica específica que atañe a la materialidad de los lenguajes. Del lenguaje literario en Mallarmé, Joyce y Artaud, del lenguaje plástico en Munch, en Picasso, Braque y los primeros futuristas, del lenguaje musical en Satie, en Shöenberg, en Varèse. En estos campos se opera una revolución que por ser distinta no se incluye en la gesta de las revoluciones socialistas y comunistas. Sin embargo, estas utopías artísticas conmovieron profundamente el campo cultural. El deslizamiento metonímico del deseo hacia la transformación de una realidad situada en el terreno estético significa un direccionamiento de la práctica de nuevos lenguajes en un campo productivo determinado. Esa productividad está también dirigida hacia la transformación de la realidad y, en este caso, las leyes de la significación corresponden a leyes objetivas naturales de transformación social.

En relación a esta revolución complementaria de la revolución social Artaud dice:

Existe en este punto una revolución que debe hacerse a condición de que el hombre no se piense revolucionario solamente en el plano social, sino que crea que debe serlo sobretodo en el plano físico, fisiológico, anatómico, funcional, circulatorio, respiratorio, dinámico, atómico, electrónico... Confirmando esta constatación el nombre de Lénin se mezcla con el de Nerval, de Nietzsche, Villon, Lautréamont, Edgard Poe (Artaud, 1947).

Unir la contradicción heterogénea que subyace en los lenguajes artísticos revolucionarios a la crítica revolucionaria del orden social establecido es lo que resulta intolerable para la ideología dominante y para sus mecanismos de liberalismo-opresión-defensa.-

Mallarmé hace su revolución casi exclusivamente en la práctica del texto donde compara la actividad literaria a la explosión de una bomba, una suerte de atentado anarquista que debía ser llevado hasta sus últimas consecuencias, hasta abolir el dogma más tenaz: el de la codificación del lenguaje, última garantía de la sociedad instituida.

"Los gobiernos cambian pero la prosodia permanece intacta ya sea porque ella pasa desapercibida en las revoluciones o porque se supone que es imposible cambiar este dogma último que no puede variar y no merece ser objeto de un atentado" (Mallarmé, 1964).

Artaud también propone un dispositivo revolucionario verbal, escénico, pictórico similar a una explosión "bombas que deben ser puestas en la base de la mayor parte de los hábitos de pensamiento actuales europeos o no" (Artaud, 1975).

En la época de las grandes revoluciones sociales y artísticas la vanguardia interpreta los "furores colectivos" de la sociedad.

En relación a esto Artaud sostiene:

El arte tiene el deber social de dar salida a las angustias de la época. el artista que no ha abrigado en el fondo de su corazón, el corazón de su época, el artista que ignora que es un chivo expiatorio, que su deber es imantar, atraer hacer 
caer sobre sus hombros las cóleras errantes de la época para descargarla de su malestar psicológico, ese no es un artista...

No todos los artistas son capaces de alcanzar esa especie de identificación mágica de sus propios sentimientos con los furores colectivos del hombre Y no todas las épocas son capaces de apreciar la importancia del artista y de la misión de salvaguarda que ejerce en beneficio del bien colectivo (Artaud, 1975).

Sin embargo, hay momentos históricos en los que no alcanza con salvaguardar y el artista debe participar de la movilización popular para transformar, junto con otros sujetos, el proceso de la historia y la sociedad.

\section{Creatividad}

Si bien tanto Mallarmé como Artaud consuman una militancia en el plano creativo del lenguaje estético y asumen integralmente sus riesgos su militancia política no es enteramente concomitante. Es el Surrealismo, (grupo de artistas al que Artaud perteneció pero al que no acompañó en todas sus revindicaciones políticas) y también las vanguardias latinoamericanas de la época, el Creacionismo chileno, el Antropofagismo brasileño, el Estridentismo mexicano, el Euforismo portorriqueño, el movimiento que se crea en Perú en torno a la revista El Amauta dirigida por José Carlos Mariátegui, quienes se transformarán en laboratorios de ese lenguaje poético para transformarlo en expresión política. Esos laboratorios estéticos donde van a buscarse las transgresiones y el goce que escapan a las estructuras reglamentadas, desplazan a menudo la escena de la acción hacia estratos subconscientes, oníricos y utópicos.

Breton propone en el primer manifiesto del surrealismo:"Cambiar la vida dijo Rimbaud, transformar el mundo exigió Marx para los surrealistas estas dos consignas son una sola" (Breton, 1992).

De esta manera extrae definitivamente el lenguaje poético de la escena literaria para difundirlo en el campo social y político. La verdad que los textos surrealistas significan no una verdad única sino plural e incierta, el objeto denotado es puesto en proceso. El tiempo ya no es el tiempo lineal sino una multiplicidad de instantes.

El acto creativo considerado bajo esta nueva óptica se arroga el mérito de engendrar el goce introduciendo la topología pulsional no en el entendimiento o la comprensión sino en el movimiento del concepto y su desplazamiento, diseminación, deconstrucción.

El arte contemporáneo revela una práctica específica cristalizada en modos de producción altamente diversificados que tienen en común el lenguaje poético que se alimenta de aspectos oníricos y de azar.

Estos discursos cambian radicalmente el sentido de las concepciones creativas y establecen una suerte de corte epistemológico con el pasado. Se podría incluso establecer una teoría, en el sentido de un discurso analítico, acerca de los sistemas significantes que cambian de signo y redireccionan el fenómeno creativo. Este nuevo discurso se apartaría de las teorías aceptadas y reconocidas acerca 
de la creatividad para proponer ejes teóricos nuevos que respondan a estas crisis revolucionarias del sentido, a los procesos del sujeto y a la estructura de los discursos. Esta readaptación de las teorías de la creatividad actualmente aceptadas y en curso consistirían en tratar de encontrar no los contenidos sino el topos del procedimiento teórico formal. Tratar de encontrar las condiciones reales de producción de una teoría no significa elucidar sus evidencias como tales sino analizarlas, desmontarlas, deconstruirlas para mostrar el origen dialéctico de aquello que se muestra como evidente.

Esto equivale a plantear una teoría como un espacio heterogéneo del que forman parte el sujeto creativo, tanto como la base económico-social en la que se despliega su práctica (Valdés, 2004).

Barthes decía que arte es aquello que el hombre arranca al azar. Este punto de vista es una derivación de los planteos de Paul Valéry quien afirmaba que una obra es la interrupción casual de un proceso de configuración que virtualmente puede continuar, no tiene, entonces, nada vinculante. De esta manera es el público receptor el que adquiere un papel preponderante ya que un modo de entender una configuración no es menos legítimo que otro. Ni siquiera el creador de la obra posee la clave de su interpretación. Cada encuentro con una obra es una nueva producción originaria. Valéry saca estas conclusiones para eludir el mito de la producción inconsciente del genio. De esta manera traslada al espectador y/o al intérprete el poder creativo absoluto. El tema de la crítica consiste en determinar el carácter hermenéuticamente vinculante que le corresponde a la obra dentro del proceso creativo. Vista tanto desde el punto de vista del creador como de quien la enfrenta para disfrutarla o refutarla la obra es, en cualquier caso, una experiencia de sentido, sentido que puede tener un trasfondo sensual y retiniano. Matisse decía que es el color el que remueve el fondo sensual de los hombres. O puede tener un carácter intelectual como el que Duchamp buscaba proyectar en sus obras. Puede ser también un sentido delirante e irracional pero es siempre un sentido al fin.

Hay un campo intermedio interesante en la creación que esta configurado por las artes reproductivas. Una obra musical o una obra de teatro que vinculan de una manera particular al intérprete con el creador, lo liberan de hacer una mera imitación del modelo Gadamer en su obra de 1958 El cuestionable carácter de la cuestión estética dice:

La interpretación es ciertamente recreación pero este recrear no sigue un acto de creación previo, sino a la figura de la obra creada, teniendo sólo que llevarla a su representación según encuentra sentido en ella... Ahora bien la interpretación reproductiva tiene su propio material autónomo y con él una tarea de formación originaria que faltan en el interpretar comprensivo, por lo tanto también, por ejemplo, en el juicio estético. Sin embargo toda interpretación reproductiva entraña comprensión y ello, muchas veces hasta tal punto que hace superflua cualquier otra discusión exegética. Pero también, a la inversa, toda comprensión y toda exégesis (Auslegen) estan construídas en dirección hacia una formación reproductiva la cual, desde luego, queda in mente... (Gadamer, 1998). 
Otro tipo de críticas, más recientes que la de Gadamer y más allá de Husserl, atacan la noción de sentido y la función del sujeto. Estas críticas delimitan la metafísica inherente a las ciencias de la significación desacreditando el significado y, con él, el ego trascendental.

Para estas nuevas corrientes la crítica también puede revestir la función poética y realizar una subversión positiva de los discursos críticos anteriores. El propio Gadamer en otro artículo más reciente Palabra e imagen cuyo título en alemán es Wort und Bild. So wahr, so seiend escrito en 1991 y publicado con sus Obras Completas (Gesammelte Werke) introduce el tema de la poiesis o de la poética, en el sentido de Paul Valery más que en el sentido aristotélico. En ese artículo se cuestiona acerca del trabajo interpretativo del crítico y se pregunta...

(...) como es posible encontrar para una obra plástica una palabra interpretativa (deutend) que no manifieste pensamientos a propósito de una imagen sino que se introduzca en una visión mejor de la imagen misma. Un tema así ocuparía un importante lugar en una teoría de la interpretación.... Un cuadro, una obra de teatro, una poesía que nos prende no experimenta ninguna restricción porque se sepa "un poco menos" acerca de ella. Así nos preguntamos qué hace de un cuadro, de un poema una obra de arte de modo que posea ese presente absoluto? No son ciertamente las quemaduras de la constante marea de la información que nos rodea y apabulla y que acompaña a la época de la reproductibilidad. Antes bien, por así decirlo con Benjamin (o contra él) ésta amenaza el aura de la obra de arte y amenaza con disolverla. En griego la palabra poiesis que podemos reconocer en nuestro vocablo poesía tiene dos sentidos .Significa en primer lugar hacer, es decir producir algo que no existía antes . la palabra comprende todo el ámbito del producir, todo lo que llamamos artesanía , pero también el desarrollo posterior de esa elaboración, hasta llegar al modo de producción industrial de la modernidad.

Además la misma palabra poiesis tenía el significado distinguido de arte poético. En cierto sentido poetizar es también hacer., es decir el producir algo que no existía antes . La palabra comprende todo el arte del producir. Mas no nos referimos con ello al decir al decir algo una vez no a la mera anotación que se hace casualmente. El hacer del que aquí se trata se refiere al texto. El hacer que a partir de la nada puedan abrirse mundos enteros, y que el no-ser llegue al ser (Gadamer, 1998).

Esta noción de poética se ha transformado a partir de los años 90 en la herramienta crítica más utilizada para abordar las nuevas formas de arte: instalaciones, instalaciones multimedia, performances, apropiaciones, que plantean a la vez el arte conceptual y el concepto de arte. En Art after Philosophy (1969) Joseph Kosuth delinea una definición propia de lo que sería arte conceptual separándolo de otras poéticas "impuras". Para este artista el arte conceptual tiene como fundamento un origen analítico y lingúístico (Kosuth, 1998).

No solo las artes plásticas son escenario de este tipo de actitudes, también se verifican apropiaciones y citas en la literatura, el cine y la música. Tal como ocurre en el caso de Piglia, Godard o Cage. Estas actitudes solo pueden evaluarse con una herramienta de tipo crítico-creativo como la noción de poiesis. 


\section{Pensamiento creativo}

En el primer capítulo de su libro dedicado al Pensamiento, Hanna Arendt introduce dentro del desarrollo histórico un concepto especial de la percepción basado en la apariencia:

El mundo en que nacen los hombres abarca muchas cosas, naturales y artificiales, vivas y muertas, efímeras y eternas; todas tienen en común que aparecen, lo que significa ser vistas, oídas, tocadas, catadas y olidas, ser percibidas por criaturas sensitivas dotadas de órganos sensoriales adecuados. Nada puede aparecer, (el término apariencia carecería de sentido si no existieran receptores para las apariencias, criaturas vivas capaces de percibir, reconocer y reaccionar) - en forma de deseo o huida, aprobación o rechazo, culpa o alabanza, frente a lo que no solo esta allí sino que aparece ante ellos y tiene significado para su percepción. En este mundo al que llegamos procedentes de ningún lugar y del que partimos con idéntico destino. Ser y apariencia coinciden (Arendt, 2002).

En un mundo de apariencias el arte, como el resto de la naturaleza, se caracteriza por mantenerse quieto el tiempo suficiente como para convertirse en un objeto que pueda ser identificado y reconocido por un sujeto. En este punto las apreciaciones de Arendt coinciden con el descubrimiento fundamental de Husserl quien da cuenta de la intencionalidad de los actos de la conciencia de sí. En sus Investigaciones lógicas (1901) dice: “el complejo fónico articulado solo se transforma en palabra hablada, discurso comunicativo en general, por el hecho de ser quien habla el que lo produce con la intención de expresarse acerca de una cosa (objeto)" (Husserl, 1961). La objetividad se integra en subjetividad de la conciencia de sí por medio de la intencionalidad. Que la apariencia requiera espectadores y, por lo tanto, implique una identificación y un reconocimiento, al menos potenciales, implica que la certeza de lo que percibimos posee una existencia autónoma del acto de la percepción y puede ser compartida por otros. A este hecho Merleau Ponty lo denomina Fe perceptiva (Merleau Ponty, 1966).

Sin embargo, las apariencias no solo no revelan jamás lo que existe tras ellas sino que también lo ocultan. El propio Merleau Ponty afirma: "Ninguna cosa, ningún lado de la cosa se muestra más que escondiendo activamente los demás, denunciándolos en el acto de ocultarlos” (Merleau Ponty, 1966).

El pensamiento creativo debe procurar trascender las apariencias para descubrir y verificar los meandros de la creación misma.

El pensamiento depende estrechamente del lenguaje, al contrario de otras actividades cognitivas que parten de él o se sirven de su operatividad como instrumento. Necesita el lenguaje para articularse y expresarse para transformarse en pensamiento creativo. La finalidad del pensamiento no puede ser nunca la intuición ni puede validarse por la mera contemplación silenciosa. Bergson el filósofo de la intuición admite que: "Es asombroso que los filósofos vean tan a menudo como se les escapa el objeto que pretenden abrazar, como niños que quisieran, cerrando la mano, asir el humo" (Bergson, 1979).

El uso de la intuición tanto como el de la visión o inspiración de tipo divino ha disminuido a partir de Bergson. En Heidegger y Walter Benjamin dos de los filósofos modernos que se basan en un cierto tipo de consideraciones metafísicas el tema de la metáfora de la visión sigue, de 
cierto, modo vigente. En Heidegger el momento de la iluminación pasa como un relámpago (Biltz) y se reemplaza con otra metáfora radicalmente diferente das Geläut der Stille el son del silencio. Esta metáfora es, en cierto modo cercana a la iluminación alcanzada mediante la contemplación silenciosa. Para Benjamin la visión pasa de puntillas y es necesario aguzar los sentidos para sorprenderla.

En otras palabras para el pensamiento creativo mismo cuya estructura conceptual depende del don de la metáfora y sus variantes metonimia y sinécdoque, el problema principal parece ser que no existe ninguna metáfora para expresar ese algo invisible que opera en el interior del ser pensante y engendra objetos significantes

Todas las metáforas provienen de los sentidos y los sentidos son esencialmente cognitivos no son un fin en sí mismos sino instrumentos de conocimiento. Aristóteles en su Metafísica usa la metáfora de la energía para expresar esta fuerza interior particular. Esta metáfora corresponde a un tipo de pensamiento especulativo no cognitivo, sin embargo, tampoco es capaz de dar cuenta de este tipo de actividad particular del espíritu humano que es el pensamiento creativo. Aristóteles mismo no la utiliza más que cuando afirma que estar vivo es energein es decir ser activo por uno mismo.

Después de experimentar las dificultades de comprender el lenguaje a lo largo de la escritura de su Tractatus Logicus-Phgilosophicus, Wittgenstein publica Investigaciones Filosóficas donde se pregunta por qué piensa el hombre y responde:

Con frecuencia reprimiendo la pregunta ¿por qué? nos daremos cuenta de los hechos importantes; los cuales conducen a una respuesta. Es por ello que de manera intencional eliminaré la cuestión ¿ Por qué pensamos? para abordar la pregunta ¿Qué nos hace pensar? (Wittgenstein, 1988).

La pregunta así formulada esta mucho más ligada al pensamiento creativo o, por lo menos, a lo que consideramos como tal. Las antiguas mitologías permiten suponer que la capacidad de pensar es contemporánea con la aparición del hombre sobre la tierra, se puede, en cambio, fechar la aparición de la metafísica y la filosofía y, a partir de ellas realizar un trazado históricoanalítico de la evolución del pensamiento creativo. Si bien la palabra filosofía significa amor por la sabiduría no es obligatorio suponer que este amor haya sido más fecundo en la evolución del pensamiento creativo que la magia y el pensamiento especulativo y creador de mitos.

No hay ninguna regla que entronice el pensamiento deductivo sobre el especulativo y si la hubiera sería oportuno abolirla. En efecto, tanto el pensamiento creador de mitos como el creador de estructuras filosóficas responden a desafíos particulares y son las dos respuestas particulares a la pregunta Que nos hace pensar.

Kant escribió La crítica del juicio siguiendo el interés del siglo XVIII por el gusto y el papel que este desempeña en la estética. Lamentablemente en el propio siglo XVIII con Voltaire, quien consideraba que el mirar un espectáculo era una actitud poco significativa ya que el hombre comparte esta pasión con los monos y los perros jóvenes, se pierde la noción de valor del rol del espectador. Es bajo esta forma superficial que, en su mayor parte, el siglo XIX consideró este tema. No solo se diluyó el privilegio que tenía el espectador para juzgar, como lo postula en Kant, sino que se perdió la intuición, todavía más básica de que todo lo que aparece está allí para ser visto y el propio concepto de apariencia necesita de un espectador. 
En Hegel el espectador obtiene un lugar importante, aunque de forma elíptica, ya que toda la obra hegeliana esta dirigida a reconciliar pensamiento creativo y realidad.

Es probablemente por esto que Mallarmé, quien con su pensamiento creador consuma la empresa de conmover y deconstruir la fonética el léxico, la sintaxis y las relaciones lógicas, al mismo tiempo que el ego trascendental encuentra en Hegel una línea magistral de pensamiento tal como se puede apreciar en Igitur, Un golpe de dados... y el Libro.

Mallarmé da cuenta, explícitamente de ese interés cuando afirma que han despertado su atención "San Bernardo, el Tomás de la Summa y principalmente alguien designado por él (Villiers de l'Isle Adam) como el Titán del Espíritu Humano, Hegel” (Mallarmé, 1964).

En una época en que Hegel es poco estudiado por los filósofos franceses Mallarmé lo lee para proyectar en él su goce: "En los libros de ciencia y de filosofía pretendo gozar cada nueva noción y no aprenderla". ${ }^{1}$

En otra carta a Villiers de l'Isle Adam dice:

Desgraciadamente soy un alma regida simplemente, por el goce poético, no he podido, en la tarea previa a esta concepción, disponer de un Espíritu, como usted lo ha hecho - y usted se aterrorizará al saber que llegué a la Idea de Universo a través, únicamente, de la sensación (por ejemplo para tener una idea de la Nada absoluta he debido imponer a mi cerebro la sensación de vacío absoluto). Carta a Villiers de l'Isle Adam 24 de septiembre de 1867 (Malllarmé, 1964).

El pensamiento creativo a fines del siglo XIX y principios del XX adopta nuevas funciones formales que configuran un código semiótico en el cual la función estética asume un papel importante. Este código revolucionario se desarrolla dentro de un sistema socio-económico que no consigue cambiar la función abusiva del Estado burgués. En 1880 en Francia, por ejemplo, se suprime el descanso legal del domingo. Estas leyes represoras se instalan progresivamente después del fracaso de la Comuna de París en 1871. Es probable que las razones de este fracaso se hayan debido a que la revolución proletaria estalló demasiado pronto. El pueblo de París instruído en el socialismo utópico y el anarquismo no quería ningún poder. Deseaba una soberanía que no ejerciera poder opresor. Si bien las ideas marxistas y la experiencia de la Primera Internacional (Londres 1864) ya habían tenido lugar, las ideas de la comuna de Paris estaban regidas, sobretodo por el anarquismo como lo testimonian las novelas de Jules Vallès.

La Comuna marca la necesidad y la falta de un nuevo discurso creativo en el plano socioeconómico y político en el cual el sujeto soberano debía imponerse por encima de las Instituciones. De alguna manera, el Simbolismo, y en especial Mallarmé, se refugian en el lenguaje para producir un nuevo discurso creativo en el cual el sujeto altera radicalmente las leyes de la gramática, de la sintaxis de las relaciones lógica, en resumen de todas las Instituciones del lenguaje. Lamentablemente tal discurso revolucionario debió refugiarse en un cenáculo de élite. Sin embargo esta revolución del lenguaje poético abre la vía a las vanguardias del siglo XX que operarían tanto en el campo del arte como en el de la sociedad produciendo un discurso creativo integral. Sólo una transformación que deberá operarse en el discurso creativo del arte, al mismo tiempo que en el de la evolución económico-social, podrá crear estructuras integralmente nuevas. Frente a una dialéctica de esta índole la impaciencia revolucionaria permanece 
insatisfecha. Sin embargo, según lo ha demostrado la historia, si el discurso creativo estructural político-social y el de la superestructura están desfasados, si uno de ellos es revolucionario y el otro reaccionario la fractura se produce tarde o temprano. Es por lo tanto indispensable que los discursos creativos se armonicen en un solo pensamiento de vanguardia.

Esto es lo que esta ocurriendo en la actualidad en las movilizaciones contra la regulación financiera del mundo que tienen lugar en Europa y en U.S.A.

\section{Acción colectiva y rediseño del espacio público}

En el diseño de la movilización española de Los indignados, que este año asistieron al Foro Social Mundial de Porto Alegre, aparece esta conjunción subjetiva-colectiva que no responde a gestiones sindicales ni a partidos políticos determinados.

Antes que ella las manifestaciones del pueblo griego desde el comienzo de la crisis del 2008 y el movimiento francés contra el CPE del 2006 y contra el Tratado constitucional europeo, muestran esta nueva creatividad en el plano de la movilización popular. Los indignados españoles usan el gesto de El grito de Munch como emblema militante. Los griegos retomaron su tradición popular de la quema de muñecos en la Plaza Sintagma, los franceses diseñaron un autoadhesivo que en vez de grêve générale (huelga general) dice rêve général (sueño general) Este slogan-faro lleva a quien la pega en su solapa o la porta como pancarta a una exigencia fundamental de transformación del mundo, situación paradójica en la que el espacio colectivo se construye a través de una trayectoria individual en resonancia con millares de otras.

Una cita de Oskar Negt, representante actual de la escuela de Frankfurt sirvió de punto de partida para este slogan francés.

... Por otra parte quien no encuentra la fuerza de soñar nunca encontrará la fuerza para luchar. Esta forma de coraje cotidiano se aplica también a la ciencia. El que no encuentra la forma de soñar no encontrará tampoco la fuerza para captar realmente las cosas (Vincent, 1976). ${ }^{2}$

En realidad la crisis ha abierto una nueva audiencia y renovado el estudio de filósofos y sociólogos críticos como Foucault, Cornelius Castoriadis o Pierre Bourdieu que son abordados con un interés renovado por lo acertado de sus precisiones teóricas. También Marx es leído y estudiado a partir de una óptica nueva que conjuga el análisis de la situación actual de las organizaciones sociales con la lógica dialéctica materialista. Este interés renovado pero todavía tímido debe ser estimulado ya que es crucial para encarar la transformación de la sociedad contemporánea sobre nuevas bases Para ello es indispensable conocer la realidad histórica, si los economistas neoliberales hubieran recordado el fracaso del mercantilismo francés y de las teorías de David Ricardo y Adam Smith en Inglaterra probablemente hubieran podido reformular sus presupuestos teóricos y paliar la crisis con medidas contracíclicas keynesianas como las aplicadas por Roosevelt para salir de la crisis del 29. 


\section{Unidad dinámica de la teoría y la práctica}

Dentro de este contexto de revalorización de los textos capitales de la teoría socio-económica, no se ha abordado todavía, con una perspectiva política, la relectura de la corriente de investigación que se ha llamado Escuela de Frankfurt que, con más propiedad, debería llamarse Escuela de Teoría Crítica.

En 1923 un grupo de investigadores que se inspiraban tanto en los trabajos de Marx y Lenin como en los de Freud fundaron un instituto en la ciudad de Frankfurt para estudiar y analizar los emergentes político-sociales y culturales más destacados de la época. En especial "La huelga de masas, el sabotaje, la vía internacional del sindicalismo, bolchevismo y marxismo, partido de masas, modos de vida de las diferentes clases de la sociedad".

Los fundadores de esta escuela Max Horkheimer y Theodor Adorno, a quienes pronto se suma Walter Benjamin encararon investigaciones empíricas y teóricas basadas en la dialéctica de la heterogeneidad o dialéctica materialista planteada por Marx, concepto que moviliza la interdisciplinaridad de las ciencias sociales.

Esta escuela se mantuvo al margen de los partidos vinculados a la social democracia y al comunismo. En realidad, estos investigadores consideraban que el compromiso con un partido determinado traía aparejado el peligro de generar una visión parcial de los problemas políticos y sociales al estar condicionados por los intereses particulares de estos partidos. A la vez esta autonomía los obligaba a asumir el riesgo de la desvinculación con el movimiento obrero y las organizaciones sociales.

Los estudios filosóficos de la llamada Teoría crítica tenían como fundamento no la lógica formal de la tradición clásica sino: "La lógica dialéctica materialista que plantea las leyes generales de la producción de sistemas significantes según una heterogeneidad material y en la práctica histórica."

La realidad histórica que debió transitar la Escuela de Frankfurt, signada por la traición al movimiento obrero por parte de la social democracia y luego la destrucción de las bases obreras operada por el nazismo junto con el genocidio de judíos y gitanos, pusieron a prueba el proyecto inicial de esta escuela aunque no lograron suprimirlo. Walter Benjamin se suicida en la frontera española, desvastado por la escalada del fascismo. Horkheimer y Adorno se exilian en los Estados Unidos donde se dedican analizar la genealogía de la razón instrumental vinculada a la idea de Progreso del positivismo que había contribuido a enmascarar los problemas y a ignorar la barbarie que había surgido en los años 30 y 40. Allí emprendieron una profunda investigación de los fenómenos psicológicos y sociales que conducen a la formación de personalidades autoritarias tanto en el seno de las clases sociales dominantes como en el de las populares $^{2}$. Develaron los nuevos aspectos y las nuevas formas de la barbarie que seguían vigentes o en estado latente, incluso en países aparentemente democráticos como los Estados Unidos y Alemania después de 1945. Comprendieron, en ese momento que la crítica a la economía política era indisociable de la crítica a la industria cultural, a los medios de prensa y a todos los fenómenos vinculados de una manera u otra a la explotación capitalista. No renunciaron a las investigaciones relacionadas con la posibilidad del advenimiento de una sociedad socialista si bien se centraron fundamentalmente en los obstáculos que impedían este advenimiento. 
Después de la Segunda Guerra Mundial, la Escuela de Frankfurt fue refundada. Ese nuevo centro de investigaciones, que tuvo una gran repercusión en la Alemania Federal, nucleó gran número de estudiantes y una nueva generación de filósofos y sociólogos. Entre otros Jürgen Habermas, nacido en 1929 y Oskar Negt nacido en 1934. Estos dos investigadores encarnan las dos orientaciones opuestas que surgen en la Escuela de Frankfurt a partir de los acontecimientos revolucionarios de fines de los ' 50 y de las revueltas estudiantiles de los ' 60 .

La postura de Habermas, quien deliberadamente abandona la línea subversiva de la Teoría Crítica, está dirigida a cultivar la neutralidad académica apartándose de las acciones colectivas y los debates que agitan a la juventud y a los asalariados en esa época, hasta el punto de haber calificado los acontecimientos de Mayo del 68 en Paris como "fascismo de izquierda".

Oskar Negt, en cambio, va a constituir aquello que Alexander Neumann califica como corriente caliente de la teoría crítica, apoyándose en el término acuñado por Ernst Bloch para distinguir "la polarización histórica del marxismo europeo entre una corriente fría, doctrinaria, economicista y calculadora y una corriente cálida interesada por la subjetividad política y la realidad social" (Adorno, 2009). ${ }^{3}$

La corriente caliente de la Teoría crítica no trata de cristalizarse en un sistema. Ella sigue siendo constantemente crítica, incluso de ella misma, situándose en un sistema dinámico, en un espacio en movimiento que fluctúa entre las ciencias sociales, la filosofía, la literatura, la estética, los movimientos sociales, los sindicatos. Esta corriente no pretende establecer un espacio doctrinario ya que se esfuerza, constantemente, por poner en evidencia los dispositivos de dominación que implican situaciones de sumisión y regresión.

Es necesario aclarar que estas dos posturas cohabitan, en esa época, en el pensamiento de Theodor Adorno, quien muere en 1969. Max Horkheimer, (1895-1973) mantiene una postura más comprometida con los aspectos militantes de la teoría crítica.

Oskar Negt, quien fundó el departamento de formación obrera del sindicato metalúrgico IG Metall, sigue trabajando desde ese departamento y desde su cátedra de la universidad de Hannover algunos conceptos fundamentales como el de "espacio público opositor".

Este tema se relaciona con el de la dialéctica que se produce continuamente entre el espacio público burgués, que ha sido transformado profundamente en la época de triunfo del neoliberalismo a través de la manipulación del pensamiento popular por parte de los medios de prensa monopólicos y el espacio público proletario que, según los momentos, se retrae o se despliega arrastrando en este movimiento a numerosos grupos y movimientos sociales. Los trabajadores, los desocupados y los oprimidos.

La noción de espacio público ha sido tan difundida y banalizada como la de opinión pública. Habermas consagra a este tema varios trabajos en los que estudia su momento de aparición, en la sociedad inglesa del siglo XVII. Para Habermas el espacio público es un espacio ideal, lugar de exhibición y publicidad de ideas y saberes, un lugar de deliberación donde se debe buscar el consenso entre los ciudadanos.

Negt, analiza este espacio con otra óptica y advierte que históricamente fue utilizado por los burgueses para debatir sus divergencias y defender sus intereses descartando o neutralizando a sectores enteros de la sociedad. Bajo su control, dice Negt, el espacio público es "una síntesis social ilusoria" 1 . Los grupos sociales descartados actúan a través de asociaciones barriales, clubs, comités que ellos crean fuera del espacio público burgués que tiene la falsa pretensión de servir y representar a toda la sociedad. 
Negt cuestiona el modelo de Habermas y plantea la noción de espacio público opositor o proletario, a través de numerosos ejemplos tales como las revoluciones europeas de 1848, la Comuna de Paris de 1971, la lucha antifascista de la república española en 1936, las revueltas estudiantiles francesas de mayo de 1968. Aclara que el término proletario "no concierne solamente a la experiencia de los trabajadores, designa todas las potencialidades humanas rebeldes que buscan un modo de expresión propio" (Neumann, 2007, p. 116).

Todos los procesos que estudia son casos de desborde del espacio público burgués, un momento de encuentro del accionar de los grupos humanos cuyas vidas han sido disminuidas, quebradas, por el proceso de valoración capitalista. Quienes más se implican en este espacio opositor y proletario son los grupos sociales más desfavorecidos: los obreros, los desocupados, los jóvenes, los sin techo y todo otro grupo social que sufre la las injusticias y la violencia del capitalismo.

Negt evita incluir a todos los grupos que actúan en el espacio público en un mismo grupo indiferenciado (como hace Habermas, quien los llama ciudadanos o sociedad civil). También rechaza otras nociones abstractas y mistificadoras como República, Democracia, Estado social y Comunidad internacional. Los desarrollos teóricos de Negt integran la comprensión de la formación de la personalidad en el marco de la familia, de la escuela y de la empresa. Explica, por ejemplo, que la temporalidad espontánea con la que el niño expresa sus necesidades entra en contradicción con la temporalidad del capital que pone tempranamente en marcha un proceso disciplinario al que todo trabajador deberá someterse durante toda su existencia.

La posibilidad de una sociedad armoniosa sin guerras y sin violencia con prácticas democráticas dignas de ese nombre está ligada, para Oskar Negt todas las categorías deben organizarse y utilizar los recursos del espacio público burgués, que les pertenece por derecho. Deben salir del enclave de sus propias organizaciones, conseguir la adhesión de otros grupos afines y, eventualmente, subvertir alguna de las formas del espacio burgués.

\section{Estrategias de diseño para superar los obstáculos}

No deben ser ignorados los obstáculos que se presentan a los grupos desfavorecidos para conquistar el espacio público burgués y someterlo a una nueva lógica opositora. Uno de los principales obstáculos es el que presentan los medios de prensa que exhiben un espejo deformante de la realidad inventando historias ficticias o ignorando los temas que no responden a sus intereses. Todo esto tiene un impacto decisivo en un público que no tiene tiempo para la reflexión crítica y consume los objetos de deseo que han sido cuidadosamente creados para servir a los intereses del capitalismo. En el momento actual lo virtual, manipulado según esos intereses, sustituye las experiencias vividas por los sujetos sociales. Las vivencias de los trabajadores en sus organizaciones, sus sindicatos, sus cooperativas no alcanzan para neutralizar el bombardeo mediático de las imágenes televisivas. Estas imágenes constituyen, junto con los otros medios de prensa, un obstáculo para la comprensión de la realidad y para la movilización de las clases trabajadoras en pos de sus intereses.

Sin embargo estos obstáculos pierden su intensidad cuando un espacio opositor se despliega en las plazas, en las calles, en las universidades, en las empresas, incluso en Internet.

El punto de origen de un espacio público opositor puede ser una reivindicación limitada a un grupo particular de la sociedad como los desocupados, los sin techo, la violencia doméstica, la 
opresión de los medios de prensa monopólicos, etc. La dinámica de este espacio puede, más tarde, transformarse en la propuesta de una sociedad más justa y menos mercantilista. Como vimos en Europa y en Chile se han creado nuevos espacios opositores en los que cada participante aplica su energía y despliega sus recursos imaginativos y creativos para enfrentar la violencia que emplea el capitalismo en su proceso de apropiación de los espacios. Dentro de estos espacios se pueden enumerar históricamente en la Argentina, las marchas de los jueves de las Madres de Plaza de Mayo con sus pañuelos blancos, en torno al Obelisco, los escraches frente a los domicilios de los genocidas de la última dictadura, cuando los gobiernos de turno habían hecho prosperar las leyes de amnistía y punto final. Los escraches frente a los locales de la UCEP esa fuerza de camisas negras, creada por el gobierno macrista de la Ciudad Autónoma de Buenos Aires, que se dedicó a expulsar brutalmente a los sin techo de los espacios públicos. También pueden incluirse en este rubro las marchas de apoyo a la nueva Ley de Medios destinada a suprimir en el país los monopolios mediáticos

Este tipo de movilización no se genera en pequeños comités que se reúnen entre cuatro paredes, debe prepararse y fecundarse a través de análisis adecuados, constantemente renovados, que permitan reforzar el espacio público opositor en la ciudad de Buenos Aires. Es importante que las manifestaciones se multipliquen pero, es importante también, que ellas respondan a una visión de los problemas que supere la inmediatez del último golpe asestado por los adversarios al movimiento popular y responda a un plan de acción más amplio y coordinado. En este sentido, el pensamiento de Negt es esclarecedor y preciso. "El que se libra completamente al presente esta condenado a reaccionar siempre frente a hechos ya ocurridos..." (Vincent, 1976)2.

\section{Crisis orgánica y participación popular}

En el momento actual en que la crisis europea se profundiza día a día se advierte que por su amplitud y su aspecto inédito puede ser calificada de crisis orgánica, según la definición de Antonio Gramsci. El aumento y la generalización de las protestas populares en los países de la UE revela una ruptura entre los grupos sociales y sus formas de representación partidaria y se traduce por "el pasaje de estos grupos de la pasividad política a una forma de actividad y de reivindicación que en su unidad no-orgánica constituye una revolución" (Gramsci, 1978). Esta crisis, prosigue Gramsci, se "transforma en una crisis de poder y esto es exactamente una crisis hegemónica o crisis del Estado en su conjunto" (Gramsci, 1978). Confrontado a una situación de crisis generalizada el sistema político tiende a autonomizarse de las relaciones de representación y de los sistemas de alternancia parlamentaria. Gramsci hablaba de la tendencia al bonapartismo o al cesarismo que pudieron imponerse incluso sin César sin personalidad heroica y representativa. En un régimen parlamentario estas soluciones toman la forma de "gran coalición" que ligan de manera directa los intereses económicos y sectoriales de las clases dominantes con fracciones del personal político desvinculado de sus lazos partidarios para transformarse en aliados del capital financiero (Gramsci, 1978). Esto es lo que ha ocurrido en Grecia y en Italia donde las nuevas coaliciones gobernantes que nadie votó han sustituido a los gobernantes elegidos por el pueblo. En Grecia el socialismo se alió con la derecha del partido 
Nueva Democracia e incluso con el LAOS extrema derecha que, con esta coalición por primera vez, desde la caída de la dictadura de los coroneles en 1974, ha conseguido un ministerio.

Las máscaras han caído y la UE tanto como los Estados Unidos de Norteamérica aparecen como lo que son, empresas neocoloniales, una amenaza mortal para las reglas democráticas más elementales y cómplices declarados de la banca y el capital financiero.

Las nuevas formas de movilización popular en Europa, similares a las que tuvieron lugar en América latina, y el rediseño de los espacios públicos por parte de estas movilizaciones creativas deben ser comprendidas, más allá de su eficacia política, como una invitación a pensar la autodeterminación subjetiva e individual y la autodeterminación colectiva como un todo. Y, especialmente, como un llamado a introducir esa dimensión esencial del proyecto político de construcción colectiva que es la crítica creativa.

\section{Notas}

1. Paradójicamente Habermas construye su modelo cuando el espacio público burgués empieza a transformarse, de forma cada vez más evidente, en un espacio de manipulación de los espíritus a través de los mass media.

2. Ver sobre este punto el libro de Jean Marie Vincent La théorie critique de l'école de Frankfort (La teoría crítica de la Escuela de Frankfurt) Paris: Ed. Galilée, 1976. Un artículo de este autor La Théorie critique n'a pas dit son dernier mot (La teoría crítica no ha dicho su última palabra) se puede leer en Internet en www.theoriecritique.com

3. El prefacio introducción y conclusiones del libro de Theodor Adorno La personalidad autoritaria se puede encontrar en la Revista de Metodología en Ciencias Sociales No 12 que se puede consultar en internet o en Theodor Adorno Escritos sociológicos volumen II Madrid: Ed Akal, 2009.

\section{Referencias Bibliográficas}

Arendt, H. (2002). La vida del espíritu. Buenos Aires: Paidos, p. 43.

Artaud, A. op. cit. t VIII p. 287.

Bergson, H. (1979). Introducción a la metafísica. Buenos Aires: S XXI, p. 59.

Breton, A. (1924). Manifiestos del surrealismo (Primer Manifiesto). (1992). Buenos Aires: Argonauta p. 14.

Carta a A. Breton L' Ephémère no 11, febrero 1947 p. 8 y 9.

Deleuze, G. y Guattari, F. (1993). Qué es la filosofía. Buenos Aires: Ed. Anagrama, p. 117.

Gadamer, H. G. (1998). Estética y Hermenéutica. Madrid: Tecnos, p. 77, 291.

Gramsci, A. (1978). Cuadernos de la cárcel No 10, 11, 12, 13. París: Gallimard.

Husserl, E. (1961). Recherches logiques. Paris: P.U.F t.II, p. 19.

Lacan, J. (1978). Ecrits. Paris: Ed du Seuil, pag 372.

Mallarmé, S. (1964). La Musique et les Lettres conferencia dictada en Londres en 1894 publicada en las Oeuvres Complètes. Paris: Gallimard. 
Manifiesto para un teatro abortado Oeuvres Complétes t II (1975). Paris: Gallimard, p 25.

Mc Lelland, D. (1972). Les jeunes hegliéns et K. Marx. Paris: Payot.

Merleau Ponty, M. (1966). Lo visible y lo invisible. Barcelona: Seix Barral, p. 47-48.

Neumann, A. (2007). L'espace publique oppositionnel (El espacio público opositor). París: Ed. Payot, p. 116.

(2006). Le courant chaud de l'école de Frankfort (La corriente caliente de la Escuela de Frankfurt) Revista Variations no 12 . París.

Tony, G. (1998). Conceptual art. London: Phaidon Press, p. 14.

Valdés, S. (2004). Funciones formales y discurso creativo. Cuadernos del Centro de Estudios en

Diseño y Comunicación No 16. Buenos Aires: Universidad de Palermo junio 2004

Vincent, J. M. (1976). La théorie critique de l'école de Frankfort (La teoría crítica de la Escuela de Frankfurt). Paris: Ed. Galilée.

Wittgenstein, L. (1988). Investigaciones filosóficas. Barcelona: Crítica.

Summary: You can see today a combination of creative subjectivity and joint action. To better understand these events and analyze their scope is essential to consider the importance that, in the current scenario, have the issues of subjectivity, creativity, and their overlapping within the framework of collective action.

Key words: collective action - creativity - subjectivity.

Resumo: Hoje se pode apreciar uma combinação da subjetividade criadora e a ação conjunta. Para compreender melhor essas manifestações e analisar seus alcances é indispensável perguntar-se a importância que têm, no panorama atual, os temas da subjetividade, a criatividade e suas imbricações no marco da ação coletiva.

Palavras chave: ação coletiva - criatividade - subjetividade. 